\title{
La felicidad urbana desde la movilidad en barrios y centro de la ciudad
}

\section{Urban happiness from mobility in neighborhoods and downtown}

\author{
Dr. Ángel Emilio Muñoz Cardona', Lorena Martínez Soto PhD (c) ${ }^{2}$ \\ ${ }^{1}$ Grupo de investigación Gobierno, Territorio y Cultura, Escuela Superior de Administración Pública \\ ${ }^{2}$ Universidad Autónoma Metropolitana de México, Grupo de investigación Estudios Organizacionales \\ Correspondencia: angel@esap.gov.co \\ https://orcid.org/0000-0001-5008-0983 \\ loremar@unac.edu.co \\ https://orcid.org/0000-0001-6515-6258
}

\begin{abstract}
Resumen: El emprendimiento social en movilidad para el disfrute de una mejor calidad de vida debe ser iniciativa de los jóvenes que habitan en los diferentes barrios de la ciudad. Incluso, ellos desde sus capacidades creativas pueden llegar a diseñar modelos ejemplares de ordenamiento territorial para la movilidad responsable. Los jóvenes con formación universitaria son más sensibles al valor que tiene el diseño de ciudades más humanas; de allí, que toda transformación social en la corresponsabilidad ciudadana tenga origen en los sentimientos de simpatía, es decir, en la búsqueda de felicidad urbana para el logro de toda vida humana digna. La pregunta de investigación es: ¿Cómo motivar el emprendimiento social juvenil en barrios de la ciudad para la movilidad y fortalecimiento de la cultura ciudadana? La metodología de investigación utilizada se basó en la realización de 710 encuestas sobre Calidad de Vida y Movilidad Urbana en el Valle de Aburrá (Colombia) dirigida a jóvenes universitarios de último semestre y 8 entrevistas realizadas a: Mesas de Juventud, Secretarías municipales de Ciudadanía y de Movilidad. El estudio concluye que sí más del $90 \%$ de los visitantes diarios del centro de la ciudad viven en los barrios, entonces el fortalecimiento de la cultura ciudadana debe comenzar en los barrios. Si se organiza el barrio se organiza el centro de la ciudad.
\end{abstract}

Palabras claves: emprendimiento social, ciudad del aprendizaje, movilidad urbana, responsabilidad ciudadana, felicidad urbana.

\begin{abstract}
Social entrepreneurship related to urban mobility for the enjoyment of a better quality of life should be an initiative of the young people who live in different neighborhoods of the city. From their creative capacities, young people can design territorial models in order to promote responsible mobility. Young people with university education are more sensitive to the value of designing more friendly cities. Therefore, all social transformation based on citizen co-responsibility has its origin in feelings of sympathy, in other words, in the search for urban happiness in order to achieve a dignified human life. In this context, the research question is: How to motivate youth social entrepreneurship in city neighborhoods for mobility and strengthening of citizen culture? The research methodology was based on 710 student surveys on Quality of Life and Urban Mobility in the Aburra Valley (Colombia). The young university students belong to the last semester.
\end{abstract}


At the same time, 8 interviews were conducted: Youth Tables, Municipal Secretaries of Citizenship and Mobility. The study concludes that if more than $90 \%$ of the daily visitors to the city center live in the neighborhoods, the strengthening of citizen culture must begin in the neighborhoods. If the neighborhood is organized, the city center is organized.

Keywords: social entrepreneurship, learning City, urban mobility, citizen responsibility, urban happiness.

\section{Introducción}

La economía naranja (industrias culturales y creativas) a diferencia de la economía de mercado se basa fundamentalmente en los proyectos sociales como respuesta a las necesidades locales (Duque, 2018). Dichos proyectos sociales nacen de la capacidad creativa y de resiliencia que tienen los residentes del barrio, para evitar los deterioros de la calidad de vida de algunos miembros de su comunidad y, por tanto, sirven a la construcción de las agendas públicas locales. Afirmó Adam Smith (1997a) en la Investigación sobre la Naturaleza y Causas de la Riqueza de las Naciones:

"Las personas definen sus necesidades según las costumbres locales que dan las mercancías necesarias para una vida digna y cuya falta constituiría, en cierto modo, algo indecoroso entre las gentes de alta y baja reputación. El no consumo de estas mercancías necesarias bien por la costumbre o por la falta de ingresos provocan vergüenza. Un honrado jornalero se sonrojaría si tuviera que presentarse en público sin calzado. La costumbre ha autorizado el uso del calzado como algo necesario para la vida, hasta el extremo de que ninguna persona de uno u otro sexo osaría aparecer en público sin él" (Smith, 1997a, p. 769).

Es decir, las necesidades cambian entre habitantes de distintos países, territorios y localidades; dependen de las capacidades de conocimiento y de unión solidaria de los residentes, en otras palabras, de los desarrollos locales socialmente alcanzados. Mientras en un país desarrollado las telecomunicaciones son satelitales, en un país en desarrollo son por cable de antena, o mientras en una familia de una localidad de clase alta en Medellín (Colombia) la necesidad está en el cambio de modelo del vehículo de hace cinco años; para unas familias de una localidad de clase baja está en pintar las fachadas de sus casas. Si el hombre es por naturaleza un ser social (Smith, 1997) la superación de las necesidades se convierte en un lenguaje común, en lo que es habitual o natural, en lo que es comunalmente aceptado porque es connatural para todos (Muñoz Cardona, 2017, p. 19).

De allí, que para evitar el decaimiento social entre las clases sociales más pobres e igualar formas de vida socialmente aceptables, el escocés Adam Smith (1997a, p. 688), aconseje mostrar a los habitantes de los ayuntamientos más pobres cómo viven los habitantes de las localidades más ricas, de esa manera, los individuos serán conscientes de que existen mejores formas de vida, es decir, más organizadas; por lo que ellas buscarán, por naturaleza, cómo alcanzarlas, cómo mejorar las que se tienen. De esta manera, el país y la ciudad evitará el decaimiento social de los más pobres. Evitará la existencia de males futuros peores en el debido orden social (Smith 1997, p.p. 228-230).

Siguiendo el principio smithiano de ordenamiento de ciudad alrededor de la satisfacción de las necesidades comunes, el cual se fundamenta en tres grandes supuestos teóricos: primero, el hombre es por naturaleza un ser social; segundo, el hombre es por naturaleza un ser sintiente, y tercero, el hombre por naturaleza busca lo que es bueno o mejor para sí mismo y los suyos. Podríamos afirmar que, el ser humano aprende de las experiencias y es capaz de condolerse por el otro, es decir, es un ser sensible-racional, perfectible y ama lo que es bueno para sí, los suyos 
y los demás; pues su bienestar está ligado al bienestar de los que integran la localidad (Smith 1997, p. 228).

En la sociedad contemporánea, la tecnología y los desarrollos alcanzados en las telecomunicaciones cierran brechas diferenciales. Enseñan y ejemplifican mejores formas de vida que invitan al cambio, a la unión ciudadana para mejorar y plantear mejores hábitats. Son ciudades del aprendizaje que se transforman desde sus mismas bases comunales y de organización social (Muñoz Cardona \& Quintero, 2020).

De allí que la innovación social y la unión comunitaria se conviertan en el eje de las economías del siglo XXI. Hemos visto, por ejemplo, como un joven ingeniero libanés el 21 de marzo de 2020, ante la pandemia internacional del Coronavirus, en la celebración del día de la madre en su país usando un dron entregó rosas en las manos de las agasajadas; las ganancias obtenidas fueron entregadas a organizaciones sociales para atender la mortal enfermedad. Ese tipo de iniciativas mitigan las necesidades, evitan los sentimientos de vergüenza del hijo al hacerse presente el día de la madre, e hinchan de orgullo social al joven ingeniero que dio solución a las necesidades y fue ejemplo de solidaridad nacional ${ }^{1}$.

De igual manera, 13 jóvenes de la ciudad de Medellín se hicieron amigos a través del enlace: “@deldichoalhechocol”, y con un capital de 6 millones de pesos (1400 €) salieron en tres vehículos a diferentes lugares del territorio, para ayudar a vendedores ambulantes que por sus penurias económicas no pueden guardar la cuarentena, decretada por el gobierno departamental para el control de la pandemia del coronavirus. Los jóvenes ayudaron a 20 personas y crearon una gran red de solidaridad ${ }^{2}$. Ejemplos de liderazgo comunitario fortalecidos en los jóvenes desde los centros de formación profesional, algunos de ellos trabajan con el Centro de Integridad de la Universidad EAFIT, el proyecto de Integridad, Respeto y Tolerancia: \#RespetoEn EAFIT y del Centro de Investigación Ética y Bioética de la Universidad Pontificia Bolivariana.

A través del enlace \#DonatónPorMedellín liderado por la Fundación EPM y el joven burgomaestre de la ciudad lograron recolectar, en solo 14 horas más de 100.000 mercados de alimentos y más de 13.316 millones de pesos para las familias más afectadas por el paro laboral decretado por la cuarentena; una gran jornada de unión ciudadana, empresarial, municipal y de jóvenes artistas de la región en solidaridad con la ciudad, de amor por la ciudad y sus ciudadanos ${ }^{3}$.

Estos hechos han tomado más fuerza y visibilidad social que los realizados por un oportunista que aprovechando su cargo de funcionario público y posición económica mandó a fabricar 50 carretillas para cargarlas de fruta y ser entregadas a migrantes venezolanos para que salieran a vender en el centro de la ciudad. Las ventas del día son entregadas a un administrador quien les paga 20.000 pesos diarios; actividades de la informalidad que, por no ser totalmente transparentes mantienen oculto el nombre y la identidad del funcionario. Dicho modelo de negocio de no responsabilidad ciudadana ha generado desorden social en el centro de la ciudad, problemas de movilidad y accidentes con muertes fatales de 225 peatones entre el 2018-2019. (Entrevista focal de Movilidad Urbana de Medellín, 2019; Osorio, 2019). Tal y como lo señala Ana Marín Morales en su artículo web: "El sueño colombiano: dibujando las nuevas rutas" $(15 / 02 / 2019)^{4}$, donde afirma que el uso de la carretilla se convierte en el primer

\footnotetext{
${ }^{1}$ Para una información más completa ver página web: https://www.panorama.com.ve/novedades/Las-entregan-dronesMadres-libanesas-reciben-rosas-en-su-dia-20200321-0031.html casos como este se volvieron ejemplo mundial, la mayoría de las iniciativas lideradas por jóvenes con visión de emprendimiento social y con vocación de liderazgo social servidor.

2 Para mayor información ver página web: https://www.elespectador.com/coronavirus/jovenes-en-medellin-donandinero-trabajadores-informales-afectados-por-cuarentena-articulo-910401

3 Ver página web: https://www.elespectador.com/noticias/nacional/antioquia/la-donaton-por-medellin-supero-los$\underline{10000-m i l l o n e s-a r t i c u l o-914310}$

${ }^{4}$ Ver página web de la revista londinense ROUTED: https://www.routedmagazine.com/colombian-dream
} 
instrumento usado por los inmigrantes en Colombia para transportar carga y conseguir algo de dinero. Sistema de informalidad poco controlado, tal y como lo afirmaran Wallesteirn (1974) y Lefebvre (1991), ambos autores citados por Ana Marín (15/02/2019).

La región fronteriza entre Venezuela y Colombia es un área marginal. En el libro El sistema-mundo moderno Wallerstein (1974) denomina a esto un territorio periférico que, en ausencia del Estado, se rige por la informalidad. Estas dinámicas son establecidas por aquellos que interpretan el espacio cotidianamente, como diría Henri Lefebvre (1991) en La producción del espacio: "los migrantes, los comerciantes, las mafias". Sus necesidades y las oportunidades económicas surgen de un profundo cambio social. El "rebusque", un término que ilustra los inimaginables mecanismos locales para encontrar una fuente de ingresos (por supuesto, sin ninguna regulación estatal), lleva a los propietarios de carretillas a identificar un negocio prometedor en los pasos fronterizos, donde los migrantes necesitan acarrear sus pertenencias. Las carretillas son un negocio no regulado donde los precios se negocian entre el portador y el cliente, y se calculan sobre el número de piezas de carga y la distancia (Marín, 15/02/2019).

El emprendimiento social no debe confundirse con el liderazgo comunitario, mientras el primero tiene una connotación de negocio con beneficio a una comunidad específica, el segundo hace referencia a búsquedas de formas administrativas del territorio. El emprendedor social es por lo general altruista, hace negocio con fines de utilidad comunitaria, pertenece más al modelo de las ciudades de la innovación. El liderazgo comunitario, como vocación administrativa, valora en la persona su naturaleza humana, por lo que intenta ir en busca de la equidad y la justicia social; pertenece más al modelo de las ciudades del aprendizaje, tal y como lo muestran las entrevistas realizadas a las Mesas de Jóvenes del Área Metropolitana del Valle de Aburrá5. El liderazgo comunitario no basa su administración en prejuicios sociales, políticos o religiosos. Se basa en la integración y compromiso de todos los miembros de la comunidad para el logro de los bienes comunes que demanda el barrio.

Un administrador de empresas con conductas de liderazgo comunitario se asemeja la figura hebrea de Abraham "Padre de Naciones", Modelo de liderazgo, que asumió el empresariado de la región a principios del siglo XX, afirma Restrepo (2011). El empresariado antioqueño, motivado por las creencias religiosas promovidas por la iglesia católica, concebía dentro de sus responsabilidades de fe, el deber moral de ser el padre responsable de todos sus empleados, es decir de todos sus hijos; de allí, que cada organización empresarial tuviera su iglesia y capellán, de esta manera el empresario ayudó a que cada empleado de la organización progresara en sus condiciones de vida digna: mejores viviendas, buenos centros de educación, servicios médicos, buena calidad del agua y de saneamiento básico. Así lo afirma el Ingeniero Industrial y empresario antioqueño Nicanor Restrepo Santamaria (2011) en su libro “Las élites patronales en Antioquia" cuando explica porque el desarrollo industrial en el Departamento fue diferente al resto del país y porque los afanes de comunismo, a mediados del siglo XX, no tuvo asiento real en Antioquia (Restrepo, 2011, p. 79).

Desde esta perspectiva de la filosofía práctica contemporánea, el liderazgo comunitario es producto de un modelo de construcción social, a partir de la formación y fortalecimiento de los

\footnotetext{
5 La Mesa de Jóvenes fueron creadas bajo la Ley 1885 de 2018. En ella se define una persona joven, aquella comprendida entre los 14 y los 28 años de edad, sin embargo la política de apoyo al emprendimiento joven con descuentos tributarios cubre hasta los 35 años de edad de la persona. Una de las principales definiciones de la Mesa de Juventudes en el Artículo 5 es: Son espacios de participación de las juventudes. Son todas aquellas formas de concertación y acción colectiva que integran un número plural y diverso de procesos y prácticas organizativas de los jóvenes en un territorio, y que desarrollan acciones temáticas de articulación y trabajo colectivo con otros actores, dichos espacios son procesos convocantes, amplios y diversos. Las Mesas de Juventudes están integradas por jóvenes universitarios de ciencias humanas, artes plásticas y sociales, principalmente. También la integran líderes sociales con bajos niveles de estudio, especialmente se secundaría. Son personas muy sensibles a los problemas sociales y económicos que viven sus comunidades.
} 
sentimientos de simpatía y de la acción solidaria. Si bien algunos movimientos sociales y de partidos políticos creen ver en el liderazgo comunitario el resultado de una acción particular; el presente ensayo de investigación lo presenta como una acción que gana fuerza dentro del apoyo social, es decir, trasciende lo personal. Ya que, si bien la idea puede nacer de un individuo, el logro del objetivo demanda del apoyo comunitario; pues el hombre es por naturaleza un ser social, lo que va mucho más allá del yo personal (Muñoz Cardona, 2017).

Hechas las anteriores aclaraciones, el presente ensayo de investigación muestra la importancia del liderazgo comunitario en la construcción de la felicidad urbana para la movilidad desde los principios filosóficos de la simpatía y de la acción solidaria por mejores entornos sociales y de convivencia. Para ello, es necesario que las universidades y las organizaciones sociales formen peatones, vecinos y conductores en el deber de la corresponsabilidad. Se diseñen programas de educación vial exigentes y obligatorios que ayuden a mejorar la movilidad en las comunidades más pobres; se adopten modelos de ciudades del aprendizaje a partir de la conciencia ciudadana generalizada, como lo propone el economista (Muñoz Cardona, 2017) en la Ética de la responsabilidad ciudadana. Un camino para la paz

\section{Breve caracterización del área metropolitana del Valle de Aburra}

El Área Metropolitana del Valle de Aburrá comprende un área de $1.157 \mathrm{Km} 2$ conformada por 10 municipios: Caldas, Sabaneta, La Estrella, Itagüí, Envigado, Medellín, Bello, Girardota, Copacabana y Barbosa. La ciudad núcleo es Medellín, capital de Antioquia y es reconocida a nivel internacional como ciudad de la innovación y del aprendizaje. El Valle de Aburrá esta entre dos grandes cordilleras que le dan su belleza paisajística y frescura. Según el Departamento de Estadística Nacional, el área metropolitana posee una densidad poblacional de 3.800.000 habitantes aproximadamente. Posee un parque industrial de 535 grandes empresas, 1.643 medianas empresas, 5.900 pequeñas empresas y 71.302 microempresas. El empleo informal representa cerca del $53 \%$, el sector público genera cerca del $11 \%$ del empleo total y el sector privado el $34 \%$. Aproximadamente el $80 \%$ de la población gana menos de 3 salarios mínimos, el $12 \%$ entre 4 y 10 salarios mínimos y el $8 \%$ más de 11 salarios mínimos (DANE, 2018). Los municipios de Medellín, Sabaneta, Itagüí, Copacabana y Envigado han sido reconocidos a nivel nacional como los municipios de mejor calidad de vida desde principios del año 2000 entre los 1.122 entidades administrativas locales del país.

\section{El concepto de felicidad urbana}

El concepto de felicidad urbana ha tomado especial significado en los fenómenos de conurbación propios de las ciudades de aglomeración. Afirma en Colombia la Ley 1625 de 2013 sobre la conformación de áreas metropolitanas, que entre las finalidades de las uniones municipales está la planificación del territorio para el bienestar de los ciudadanos. Dentro de ese bienestar se incluye la infraestructura urbana: mejores aceras peatonales, parques y de espacios públicos para el disfrute y movilidad de las personas. Los crecimientos industriales demandan crecimientos urbanísticos para la movilidad que a su vez sean humanos. Una ciudad mal planificada puede convertirse en una trampa mortal para el peatón; en un abandono acelerado de los espacios públicos, como lo afirmara Jane Jacobs (2011) en Muerte vida de las

\footnotetext{
${ }^{6}$ Las ciudades del aprendizaje son ciudades que se transforman y progresan a partir de las iniciativas comunales de organización administrativa del territorio. Son ciudades resilientes, es decir, capaces de aprender de las experiencias. Las ciudades del aprendizaje son ciudades en las que todos aprenden de todos. Generalmente, los barrios pobres cuentan con jóvenes universitarios que estudian en las mejores universidades públicas de la ciudad. Ellos son la materia prima fundamental del cambio. Son personas que saben escuchar y transformar las ideas artesanales en ideas técnicas. Las ideas comunitarias que se logran transformar en ideas reales se convierten en ejemplo administrativo público, y pueden pasar a ser parte de las agendas locales de gobierno.
} 
grandes ciudades o más recientemente Jan Gehl (2014) en su concepto de diseño de ciudades para la gente.

El concepto de felicidad urbana en movilidad da cuenta de los espacios reales y efectivos que tienen las personas para el disfrute de los espacios abiertos (Fernández, 2019), para caminar junto con y hacer uso de sus capacidades naturales del lenguaje: hablar, gestualizar, socializar y aprender del otro e incluso de lo otro. En ciudades más avanzadas en movilidad de Canadá, Europa y América Latina el gesto moderado o mínimo y la mirada de asombro de peatones prudentes educa al imprudente; al inculto que por sus afanes arriesga su salud, la tranquilidad y bienestar emocional de otros (Ribetto, 2014).

De allí que la Ley 1625 de 2013 en Colombia invite al ciudadano y a las localidades a encausar los espacios públicos para mejorar las condiciones y niveles de calidad de vida a través de programas educativos y culturales que busquen bienestar colectivo. Incluso en el Artículo 536 de los Planes de Ordenamiento Territorial, Ley 388 de 1997 y en el Artículo 278 de la Ley 1955 de 2019 en Colombia, han creado mecanismos de financiación de proyectos de espacio público e infraestructura que pueden ser financiados a través de las titularizaciones o de emisión de bonos de deuda pública pagados a futuro con la valorización de los predios

Sin embargo, la falta de cultura ciudadana en el uso adecuado de los espacios públicos en barrios de las grandes ciudades del Área Metropolitana del Valle de Aburrá aunado al crecimiento poblacional, número de vehículos y atraso en el desarrollo de infraestructura vial para la movilidad, hacen de dichos lugares, espacios inseguros para peatones con movilidad reducida, mujeres en gestación, niños y adultos mayores. Dichas inculturas de comportamiento ciudadano en el respeto a espacios públicos en barrios del Valle de Aburrá son trasladados al centro de la ciudad. Lo que aumenta los índices de accidentabilidad.

\subsection{Indicadores de felicidad urbana}

Si bien el concepto de felicidad general, es decir, de todos los que viven en la ciudad, es leído en la Grecia antigua de Aristóteles y Epicuro, también es leído en los albores de la sociedad moderna con el nacimiento de la economía, y en la sociedad contemporánea en los gobiernos de Buthán, Países Bajos, Dinamarca y Suecia (Muñoz Cardona \& Quintero, 2020). El concepto de felicidad general, dentro de las sociedades contemporáneas, es asociado a la satisfacción de condiciones de vida digna. Entre las 16 variables que incluyen los estudios de felicidad general se tienen: Salud con calidad, Educación con calidad, Diversidad ambiental, Nivel o costo de vida, Gobernanza y transparencia, Bienestar de la población, Uso del tiempo libre, Vitalidad comunitaria e inclusión social, Cultura, Nivel de Ingresos, Desempleo y Empleo, Satisfacción con la vida o Proyecto de vida, Necesidades Básicas Insatisfechas, Esperanza de vida, Movilidad y seguridad y Precio de la propiedad

Mientras el Producto Interno Bruto evalúa 4 variables de crecimiento empresarial o de producción -Consumo, Gasto Público, Exportaciones Netas e Inversión. El índice de Felicidad Interna Bruta FIB de Bhután evalúa el desarrollo o el bienestar social y económico a través de 9 variables:

1. La salud y la calidad del acceso a los servicios de salud. 2. La calidad de la educación como preparación para la vida o para el trabajo, la satisfacción personal y la vida en comunidad. 3. La Diversidad ambiental. -acceso a servicios ambientales y los conocimientos de la población en las bondades ambientales y el número de árboles sembrados por persona. 4. El Nivel de vida. Mide los consumos de los hogares - calidad y frecuencia en el consumo de los alimentos -, el número de casas propias y arrendadas, tipo y calidad de las viviendas, hogares con carencia de servicios públicos básicos domiciliarios, el disfrute de aceras y de calles pavimentadas. 5. Gobernanza. En este se evalúa la calidad de los servicios públicos que ofrece el Estado, la confianza en las instituciones de gobierno - tanto de la administración pública como de los organismos de seguridad -. 6. Bienestar de la población en términos de los sentimientos de seguridad laboral y de movilidad, generosidad, preservación de valores culturales y la 
tranquilidad. 7. Uso del tiempo. Allí se cuantifica la calidad del tiempo que las personas dedican a dormir, al trabajo, al disfrute con los vecinos, a la educación, a la familia, a los juegos, al deporte y a meditar, entre otros. 8. Vitalidad comunitaria. Aquí se estima la confianza y apoyo social entre los miembros de una comunidad para la consecución de bienes comunes, así como el apoyo socioeconómico que entre todos se brindan. 9. La Cultura. Evalúa el conocimiento que sobre la cultura del país poseen los habitantes, sus símbolos, su historia y sus festividades más importantes.

En el 2011 en la celebración de los 50 años de fundación la Organización para la Cooperación y el Desarrollo Económico OCDE, se lanzó el índice para una vida mejor "Better Life Index BLI"; en él se toman en cuenta: los ingresos disponibles por hogar, la tasa de desempleo y de empleo, número de habitaciones por hogar, esperanza de vida al nacer, tasa de mortalidad por rango de edad, nivel de educación, calidad del aire, tasa de homicidios, participación electoral, hogares con internet, redes sociales y satisfacción con la vida. El índice se calcula para 34 países miembros de la OCDE. El BLI reabrió a nivel internacional la discusión de las economías del bienestar sobre las diferencias en los significados de crecimiento económico y progreso social.

El Happy Planet Index HPI, mide: la calidad del bienestar económico de los residentes de un país (wellbeing), las expectativas de vida, la equidad o inequidad de los ingresos entre las personas de las distintas regiones, el disfrute ecológico per cápita y la participación social en las decisiones del gobierno. Es un indicador centrado en los fortalecimientos de la democracia ampliada y disfrute de los espacios públicos sostenibles, en otras palabras, en la unión solidaria para la conservación de los recursos naturales.

Amartya Sen, Joseph Stiglitz y Jean Paul Fitoussi propusieron el indicador de Bienestar Pluridimensional BP, en él se evalúan: las condiciones de vida materiales -ingreso, consumo y riqueza-, la salud con calidad, la educación como formadora de capacidades reales, las actividades personales en tiempos de ocio, la calidad del trabajo, la participación en la vida política, la gobernanza, las relaciones sociales entre vecinos, el medio ambiente a presente como a futuro y la seguridad laboral (Stiglitz \& et al., 2015). El índice de BP se centra en los mejoramientos de las condiciones de vida y de vida buena de la población, esto es: acceso a bienes públicos fundamentales, condiciones del hábitat o de relación con los vecinos, de las oportunidades de autorrealización y de satisfacción con el gobierno, la transparencia de las instituciones públicas.

El Índice de la Calidad de Vida ICV toma en cuenta: El costo de la vida, los precios de la propiedad, la tasa de crimen o de criminalidad, el cuidado de la salud, el tráfico vehicular, los niveles de contaminación, el acceso y la calidad a los bienes públicos fundamentales. La economía del bienestar, desde la nueva gestión pública, basada en los principios del bienestar general se centra en los mejoramientos de las condiciones de vida de la población y de vida buena dentro de las ciudades, en otras palabras, en las inversiones públicas para la movilidad, el disfrute de recursos naturales, en espacios para el encuentro de experiencias y nuevos conocimientos.

El Social Progress Index SPI diseñado por la Social Progress Imperative Organization, evalúa: las necesidades básicas -cuidados médicos básicos, agua y sanidad, abrigo y seguridad personal-, acceso a conocimiento básico, acceso a información y comunicación, bienestar, salud y calidad del ambiente, derechos personales, acceso a la educación, tolerancia e inclusión. Lo que Jan Gehl (2010) llama ciudades para la gente o lo que Max-Neef, Elizalde y Hopenhayn (1994) llaman desarrollo a escala humana, tanto de las condiciones del hábitat como de la relación interpersonales con los vecinos, o lo que Maslow (2008) denomina las oportunidades de autorrealización.

El Banco Interamericano de Desarrollo (BID) y el economista colombiano Eduardo Lora, han estudiado sobre políticas de regionalización para el monitoreo de la calidad de vida en las ciudades; entre los indicadores más significativos han encontrado: el precio del mercado de la 
vivienda y la satisfacción con la vida de las personas (Lora \& et al., 2010). En los precios del mercado de la calidad de la vivienda; se toma en cuenta, el tipo de vecindario, la tranquilidad y la seguridad que ofrece a sus moradores, tales como: el estado de los andenes, la cercanía de centros comerciales, la oferta de juegos infantiles, las facilidades de transporte, la disponibilidad y prontitud de la fuerza pública para la atención ciudadana, la cercanía de escuelas y colegios, la limpieza del aire, los niveles de ruido y de zonas verdes. Estas variables ayudan a explicar la baja movilidad, es decir la amplia demanda y la baja oferta habitacional que disparan los precios de la vivienda o del alquiler de esta en el sector.

En el nivel de satisfacción con la vida que poseen los individuos, lo que tiene que ver con el entorno en el cual vive y con las facilidades de logro del proyecto de vida (Lora et al., 2010). En este ítem se evalúa: el clima de seguridad, la cercanía y la calidad de los programas que ofrecen los centros culturales y deportivos para adolescentes, jóvenes y adultos mayores; la pertinencia de las acciones comunales o entidades del Estado en pro de la conservación de la paz y de la sana convivencia; el nivel de educación en el trato respetuoso entre los vecinos, los niveles de tolerancia, la calidad de los servicios públicos y de aseo en la región; las expectativas de superación personal coadyuvadas por la calidad de los centros de formación - escuelas y colegios- presentes en el sector ${ }^{7}$.

El índice de felicidad urbana IFU del grupo de investigación: Gobierno, Territorio y Cultura de la Escuela Superior de Administración Pública de Antioquia, evalúa el bienestar de la población joven universitaria de último semestre en las ciudades del área metropolitana de la cultura antioqueña: del Valle de Aburrá, Manizales, Pereira y Quindío. El Instrumento de encuesta comprende tres variables: Caracterización sociodemográfica, Satisfacción con los recursos y Pertenencia a la comunidad. El estudio de felicidad urbana parte de la siguiente hipótesis: A mayor migración de la población joven de un municipio por falta de oportunidades para la autorrealización menores son las posibilidades de desarrollo y crecimiento del municipio. Por el contrario, a menor migración de la población joven de un municipio por abundantes oportunidades para la autorrealización mayores son las posibilidades de desarrollo y crecimiento del municipio y sus localidades.

A partir del bienestar subjetivo como eje de felicidad, el índice de felicidad integral IFI de la ciudad de Medellín, evalúa, a través de ocho dimensiones y 22 categorías, la felicidad subjetiva de los medellinenses. Ellas son: 1). Vida: en ella se miden estándares de calidad de vida, satisfacción con la vida, experiencias emocionales, usos del tiempo libre e igualdad de oportunidades. 2). Experiencia de Felicidad: se mide las experiencias de felicidad sentidas por la ciudadanía y la distribución de la felicidad en términos de la equidad del gasto público. 3). Entorno: participación cultural y deportiva, satisfacción con la oferta pública inmobiliaria o de equipamiento de ciudad, recursos naturales, espacio público. 4). Salud: estado de salud y actividades saludables de la población, bienestar psicológico y valoración del sistema de salud por la ciudadanía. 5). Seguridad y Convivencia: percepción ciudadana de la seguridad, victimización y convivencia. 6). Educación: asistencia escolar y pertinencia de la educación. 7). Buen gobierno y Ciudadanía activa: participación ciudadana, gobernanza, libertad de expresión, libertad de opinión y confianza en el gobierno. 8). Movilidad Urbana: valoración de la movilidad peatonal y de vehículos (Plan de Desarrollo Municipio de Medellín, 2016; El Mundo, 20/03/2017).

El IFI de Medellín se basa en el indicador de felicidad de Pemberton Happiness Index, el cual posee dos componentes de medida: una referida al bienestar social en términos del disfrute

\footnotetext{
7 Es un deber de las escuelas y colegios formar a los niños y adolescentes en la conciencia ciudadana del respeto al vecino y a la comunidad. Enseñarles, por ejemplo, el amor por el entorno y la calidad del hábitat, el debido respeto por el espacio público, como el de no arrojar basuras a fuentes hídricas cercanas, no escuchar música a altos decibeles, fumar marihuana o consumir estupefacientes en zonas públicas o al pie de las puertas de las casas de los vecinos, escuelas y colegios.
} 
de bienes materiales y otra referida a la suma de experiencias positivas y negativas vividas. Pero a diferencia del IFI el Pemberton Happiness Index, toma en cuenta la cultura. El IFI como el IFU de la ESAP de Antioquia evalúan el bienestar social en términos del disfrute de bienes comunes, y la satisfacción con las instituciones democráticas como forjadoras de bienestar futuro. Es decir, evalúan la vitalidad comunitaria: el altruismo o del trabajo solidario para el logro del bienestar comunal (Muñoz Cardona \& Quintero, 2020). De allí la importancia que para la Organización de las Naciones Unidas ONU reviste el día internacional de la felicidad, no como día festivo sino de reflexión social sobre los logros alcanzados en el bienestar social de las personas a partir de las acciones de los gobiernos (Resolución 66/281, 2012).

La ONU en la resolución (A/RES//65/309) establece que el indicador de crecimiento del producto interno bruto PIB, no refleja la felicidad y el bienestar de las personas de un país, ni tampoco el desarrollo sostenible, la erradicación de la pobreza, la felicidad y el bienestar de todos los pueblos, por lo que recomienda, a todos los países miembros, en aras del cumplimiento de los Objetivos de Desarrollo del Milenio:

1. La elaboración de nuevos indicadores de felicidad social, como objetivo y aspiración universal, es la manifestación del espíritu de los Objetivos de Desarrollo del Milenio.

2. Entender la importancia de la búsqueda de la felicidad general y el bienestar social como guía del desarrollo económico de las naciones y de sus políticas públicas.

3. La búsqueda de la felicidad personal es un objetivo humano fundamental, es decir es un derecho inalienable y un deber obligatorio de los gobiernos procurarlo.

4. Reconocer con beneplácito el ofrecimiento de reflexión sobre la felicidad interna bruta FIB alcanzado por el país de Bhután.

De allí que la República de Colombia, como país miembro de la ONU, adopte bajo la ley 1583 del 30 de octubre de 2012 la Resolución de la ONU A/RES//65/309, aprobada en los Estados Unidos el 19 de julio de 2011, bajo el título: “La felicidad: hacia un enfoque holístico para el desarrollo". Dando respuesta a la anterior solicitud de la ONU, el Departamento Nacional de Estadística DANE realizó en agosto del 2016 la primera encuesta de felicidad de orden nacional IFN, a 9710 personas en las 4 más grandes ciudades del país: Cali, Medellín, Barranquilla y Bogotá. La encuesta mide cuatro variables: Felicidad, Satisfacción, Preocupación y Depresión.

Entre las características de los colombianos más felices el estudio encontró: está entre jóvenes de 26 y los 35 años, tiene pareja estable, es trabajador formal, puede ahorrar, es optimista sobre el futuro, lee al menos un libro al año, tiene postgrado, tiene internet, es hombre, vive en zona urbana, vive en Medellín, está pagando su casa (DNP, 2016).

Resultados de felicidad que van muy acordes con los hallados por el IFI de la ciudad de Medellín aplicados a 511 personas (Plan de desarrollo 2016-2019, 2016; El Mundo.Com 20/03/2017) y por el IFU de la ESAP de Antioquia aplicados a 4250 universitarios de último semestre (Muñoz Cardona, 2019a; 2019b; Muñoz Cardona \& Quintero, 2020; Muñoz Cardona \& Martínez, 2020a).

\subsection{La felicidad urbana y el empoderamiento peatonal ciudadano}

Una característica común en casi todos los países del mundo es que más de la mitad de su población vive en ciudades y una característica común en casi todas las ciudades del mundo es que las personas viven en espacios públicos no pensados para ellas. El arquitecto Jan Gehl (2014) afirma en su libro Ciudades para la gente: "los obstáculos urbanos, el ruido, la polución, la poca cantidad de espacio, el riesgo de accidente son el lugar común que a diario enfrentan los transeúntes de los espacios públicos" (Gehl, 2014, p. 3). Jane Jacobs (1961) señalo en Vida y muerte de las grandes ciudades como el aumento masivo del automóvil y la ideología urbanística de las propiedades horizontales terminan por destruir el espacio en la vitalidad de la vida urbana. Ciudades que poco a poco pierden su vitalidad comunitaria, tal y como lo afirmará igualmente Peter Bosselmann (1998). Incluso, en las urbanizaciones cerradas de propiedad horizontal la vitalidad comunitaria es escasa, lugares cerrados que sólo se reúnen 
cada año para definir la cuota de administración. Una ciudad dentro de la ciudad igualmente solitaria, con espacios comunes poco frecuentados por los copropietarios.

De allí, la importancia que reviste el gasto público realizado en los diez últimos años por las grandes ciudades colombianas y del mundo en la revitalización de la vida urbana; a través de la inversión en infraestructura para el mejoramiento de los espacios y las condiciones de movilización peatonal. A principios de los años 90 en ciudades como: Bogotá, Medellín, Manizales, Sabaneta y Envigado los copropietarios residentes de las unidades cerradas disfrutan de más y mejores espacios verdes que el resto de ciudadanos y aunque fueran las unidades habitacionales más costosas para vivir por su cobro administrativo eran las más seguras. Costo de oportunidad ineludible para parejas jóvenes que buscaban tener familia en lugares seguros.

A partir del año 2000 las ciudades capitales e intermedias más dinámicas del mundo se han transformado en el diseño del espacio urbano: a través del trazado de nuevas vías para el uso de bicicletas y patinetas eléctricas, paseos peatonales y bulevares culturales; se han diseñado aceras para invidentes y semáforos peatonales electrónicos de movimiento y voz. Transformaciones urbanas que han tenido reconocimiento internacional, bajo tres modelos de ciudades: de la innovación, del conocimiento y del aprendizaje (Muñoz Cardona, 2019)8.

Si bien, ha crecido el número de vehículos en circulación, es cierto que, cada vez existen más controles para el rodamiento de vehículos en las zonas céntricas de mayor circulación peatonal, tal y como en los últimos 10 años se ha venido dando en el área metropolitana del Valle de Aburra. Sin embargo, en los barrios o comunas no existe el mismo control al tráfico vehicular; la mayoría de las viviendas adolecen de parqueaderos. De allí la necesidad de un ordenamiento territorial urbano que incluya no solo las zonas comerciales generadoras de riqueza y empleo a gran escala, sino también las zonas residenciales de los barrios, donde no existen las inversiones de alta valorización de la tierra; en otras palabras, los lugares de mayor pobreza. Un ordenamiento territorial del espacio urbano más vital, sostenible y seguro para la movilidad de las personas. Un ordenamiento que desde la política fiscal de distribución para las localidades -presupuesto participativo- eduquen los sentidos e incentiven la cultura ciudadana del respeto por el espacio público (Campanella, 1995).

Espacios públicos que inviten a caminar y motiven el encuentro social de toda la comunidad, que facilite la socialización y el intercambio de experiencias entre las distintas poblaciones; tal y como lo ofrecen los gimnasios al aire libre, las cafeterías con sillas a espacio abierto. Lugares que sirven a la recuperación de los espacios públicos, fomentan las relaciones interpersonales culturales y valorizan las viviendas locales (Lora, Powell \& Sanguinetti, 2010). Una ciudad sin fronteras invisibles; es decir, incluyentes y seguras porque permiten la circulación de las gentes que residen en el lugar como afirma (Gehl, 2014, p. 6).

Una ciudad de colores que invite a recorrerla a pie o atravesarla mediante el uso del transporte público del metro o en metro cable o en bicicleta. Los paseos peatonales adornados de zonas verdes, de bulevares culturales que fortalecen los sentimientos de simpatía y fomentan la amistad, benefician la economía del comercio formal y al medio ambiente; ya que reduce: los niveles de stress poblacional, los factores de violencia, la emisión de gases efecto invernadero,

\footnotetext{
${ }^{8}$ Las ciudades del conocimiento son ciudades basadas en la investigación y generación de nuevo conocimiento, son ciudades universitarias con proyectos de investigación académica que sirven al mejoramiento de la vida urbana. Ciudades del aprendizaje son ciudades resilientes, es decir de comunidades y organizaciones sociales que aprenden de las experiencias. Son las comunidades mismas las impulsadoras de las transformaciones sociales que sirven al mejoramiento de la vida urbana. Las ciudades del aprendizaje toma las estrategias e iniciativas ciudadanas para darles un lugar de conocimiento académico. Reconoce de la población su saber y sus buenas prácticas, lo que le da al territorio su identidad. Las ciudades de la innovación son ciudades que renuevan el uso tecnológico con creatividad y recursividad para dar solución a problemas sociales propios o domésticos. Son ciudades que se actualizan a través del uso de la tecnología -así ella haya sido inventada por otros países-, son propias de las economías naranja que impactan la calidad de vida urbana.
} 
las enfermedades cardiovasculares por sedentarismo y los niveles de ruido. Ciudades del respeto entre vecinos.

Una de las características más repetitivas dentro del estudio en ciudades de mayores niveles de ruido, como es el caso de Bello, Antioquia, fue la violencia entre vecinos, los cuales impulsaron a jóvenes teatreros de la Universidad de Antioquia y Bellas Artes a realizar campañas educativas de tolerancia en la vía pública del centro de la ciudad, tanto a conductores como peatones.

Los espacios públicos donde se combina lo intelectual con lo cultural y lo artístico, tal y como lo plantea Tommaso de Campanella en la Ciudad del Sol (1995) son lugares para la educación de los sentidos, son ámbitos urbanos más solidarios y humanos. El paseo peatonal de Carabobo en Medellín, por ejemplo, integra la administración pública -Centro Administrativo la Alpujarra- con lo artístico en la Plaza Museo Botero, con lo académico: Museo Arqueológico de la Universidad de Antioquia, RUTAN, el observatorio astronómico -Planetario de Medellín- y lo lúdico con la sala de cine al aire libre: Parque Explora y el Parque Norte de atracciones mecánicas para niños y mayores. Cada uno de estos puntos a su vez son integrados por el sistema de transporte público masivo metro y estaciones de alquiler de bicicletas públicas con ciclo rutas bien señalizadas.

Afirma Jan Gehl (2014): "el interés por una dimensión humana dentro del planteamiento territorial es el reflejo de que existe una demanda por mejor calidad de vida" (p. 7), mejor disfrute, mayor felicidad urbana. Dichas inversiones para la movilidad pública generan una externalidad sobre el bien común altamente elástica, al poderse sustituir más espacios peatonales por espacios vehiculares; lo que genera mayor salud poblacional y reducción de gastos fiscales en tratamientos médicos de salud pública. Mayor eficiencia fiscal en los gastos de los gobiernos locales. Más caminos peatonales para la gente con sistemas de transporte integrado público; como lo hacen las ciudades del conocimiento y la innovación en el mundo.

Dichos lugares son generadores de cultura ciudadana, son escenarios, en términos de Campanella (1995), para mostrar como ejemplo de cómo se puede lograr un mejor comportamiento social de la ciudadanía, para generar una conciencia colectiva acerca de la importancia de respetar el espacio público, para la educación de los sentidos a través de programas lúdicos y sociales que inviten a la sensibilización tal y como lo hace la cultura metro (Muñoz Cardona, 2019). Las instituciones que más deberían liderar este proyecto de liderazgo comunitario en las comunas de la ciudad son la administración de los gobiernos locales, las universidades del sector, principalmente las públicas por financiar sus actividades de los recursos públicos.

Si se observan las calles y aceras de las comunas del área metropolitana del Valle de Aburrá es fácil darse cuenta de la incultura vehicular existente. Las vías públicas están llenas de vehículos estacionados a lado y lado de la calle, que dificultan el tránsito y aumenta la inseguridad de los peatones más vulnerables: mujeres en estado de gravidez, niños y ancianos.

Son sectores residenciales con alta densidad poblacional sin espacios seguros para la movilidad peatonal que alimentan el desorden, el estrés y los accidentes, tal y como lo afirmó (Jacobs, 1961; 2011), sin espacios públicos para la socialización de la gente o para la vitalidad comunitaria.

Los motociclistas no respetan las aceras peatonales para estacionar o transitar sobre ellas, ni las calles de los barrios para hacer acrobacia o hacerse notar conduciendo sin silenciador. De allí, los comportamientos asociales que son fuente de desencuentros y de violencia, más aún si dichas calles son estrechas. Afirma Jacobs (2011), los desórdenes de los espacios públicos los sufren más las clases sociales pobres; así mismo lo explica Jan Gehl $(2010 ; 2014)$ cuando afirma: "si se observa la historia de las ciudades, podemos ver como las estructuras urbanas y el planeamiento influyen sobre el comportamiento humano y el modo como las localidades funcionan" (2014, p. 9). 
Muchos de los barrios y de las calles céntricas municipales del Valle de Aburrá conservan sus diseños de hace más de 50 años, los cuales no dan respuesta a las crecientes demandas peatonales del 2020. Sus moradores se acostumbraron a vivir con aceras estrechas o en mal estado; es decir, con obstáculos que impiden el paso de personas de movilidad reducida. Espacios públicos en mal estado; vías que son disputadas por peatones y vehículos. Calles que no facilitan el control de las autoridades ante la falta de conciencia en el uso y respeto de los espacios públicos. Como afirmará Jane: parece como si la seguridad de los vehículos es más importante que la de las personas (Jacobs, 1961; 2011).

De igual manera, para algunas administraciones municipales del Valle de Aburrá son más importantes los recaudos fiscales por: sanciones, el registro de nuevos vehículos, los impuestos de rodamiento y de semaforización que cumplir con la función del gasto para el cual fueron creados dichos gravámenes: mantener y ampliar la red vial. Es decir, las matrículas de nuevos vehículos en: Itagüí, Bello, Medellín, Sabaneta y Envigado son más importantes para el recaudo fiscal administrativo que la salud de las personas, así el número de vehículos matriculados sigan desbordando la capacidad vial de dichas municipalidades.

Afirma el urbanista Gehl (2014): “Hace ya varias décadas que la dimensión humana ha sido minimizada como una cuestión de atender dentro del planeamiento urbano, mientras otros temas, como el manejo del constante aumento del tráfico vehicular, han pasado a ser primordiales" (p. 3). Ausencias de responsabilidad y corresponsabilidad fiscal que facilitan el desorden en el uso de los espacios públicos en barrios y centros de la ciudad. Victoria Camps y Salvador Giner en el manual de civismo afirman:

"La ciudadanía hay que entenderla como una cierta dedicación y cooperación con lo público, lo que es de todos. Así, son obligaciones cívicas ir a votar, cuidar los servicios que el Estado pone a nuestra disposición, no defraudar el uso de esos servicios, pagar los impuestos que nos corresponden y hacer alguna que otra obra benéfica voluntaria en ayuda de los más desfavorecidos" (Camps \& Giner, 2014, p. 77).

No basta con que la administración pública se preocupe más por el centro de la ciudad e invierta allí todos los recursos, es necesario que ella atienda el fortalecimiento de la cultura ciudadana, la cual puede hacerla con recursos del conocimiento comunal como lo hacen las ciudades del aprendizaje. Si no se cambia el modelo administrativo de sanción por el de corresponsabilidad, la enajenación de los espacios públicos en el centro y barrios de la ciudad serán cada vez más crecientes.

Las ventas informales ocupan el espacio peatonal, dificultan la movilidad e imposibilitan el florecimiento de las actividades culturales. El no control del espacio público facilita la economía informal y subterránea en la Plaza Botero, Parque de San Antonio, Parque Berrío, Parque de Bolívar, donde se concentran un poco más del $50 \%$ de los 792.000 venteros ambulantes que tiene la ciudad de Medellín, según el censo poblacional y habitacional del DANE (2018). El comercio informal pasó del 45\% en el 2018 al 50,5\% en el 2019 provenientes de las comunas de Medellín y del Área Metropolitana9.

De allí la importancia del empoderamiento peatonal a través de los liderazgos comunitarios de los jóvenes que hacen parte de la Mesa de juventudes; de las empresas vendedoras de seguros para vehículos, escuelas de conducción; Secretarías de Movilidad y de Ciudadanía, principalmente estas dos últimas, deben diseñar programas de formación y de sensibilización ciudadana en el uso y respeto de las aceras peatonales, en la importancia del mantenimiento y manejo prudente de los vehículos. Capacitaciones que deben ser brindadas en las sedes de las Juntas de Acción Comunal y de las Organizaciones Sociales que sean aptas.

\footnotetext{
${ }^{9}$ Podría afirmarse que la ciudad ha crecido en cultura ciudadana; sin embargo, en los dos últimos años el Valle de Aburrá ha tenido un alto retroceso por el aumento de ventas informales en carretillas en un 22,22\% (DANE, 2018), principalmente por inmigrantes venezolanos. Ventas ambulantes que se han adueñado de los espacios públicos del centro de la ciudad y han facilitado la existencia de una economía de la ilegalidad y subterránea.
} 
Estrategia que además de brindarle recursos a las organizaciones sociales y comunales impulsarían programas de sensibilización para la planeación local de los espacios públicos. Incluso los Cursos Pedagógicos por Infracción a las Normas de Tránsito deberían estar acompañados de una exposición pedagógica evaluable de los infractores ante la comunidad y dependiendo del diseño, creatividad de la exposición y del impacto positivo generado en la sociedad deberá ser el valor final por pagar.

Acciones de empoderamiento para el liderazgo en servicio comunal que deben continuar siendo complementadas con las inversiones públicas como las realizadas en los últimos 25 años, las cuales buscan hallar otras formas de devolver el espacio público a la ciudadanía. Desde 1999 las acciones de la Subsecretaría Defensa Espacio Público de Medellín, por la recuperación del espacio público son contrarrestados por los mismos venteros ambulantes que a su vez son respaldados por grupos que se adueñan y alquilan el espacio público a cambio de protección y seguridad. Y por la misma población de transeúntes que no entienden la importancia de recuperar el espacio público para la movilidad segura de todos, de solidaridad con el adulto mayor, con el niño, con el invidente, con el que no tiene la misma capacidad física y desea disfrutar el espacio que es de todos.

Hechos que han obligado a la administración pública de la ciudad a realizar variadas inversiones como: reubicación de venteros ambulantes; contratación de jóvenes bachilleres para el control del espacio público; diseño de más vías azules para bicicleta; ampliación de nuevas zonas peatonales en los márgenes del centro de la ciudad como Parques del Rio, el paseo peatonal del Rio Medellín y el Parque de los Pies Descalzos; control de ingreso de venteros ambulantes al sistema integrado metro; nuevas estaciones de transporte publico eléctrico; la siembra de más de 500 árboles y especies ornamentales a lo largo de la Avenida Oriental, lo que la convierte en el primer parque lineal verde en el centro de la ciudad; y muy posiblemente antes del 2025 el cobro de impuestos a vehículos particulares que quieran ingresar a la ciudad, como lo hacen las ciudades de Londres, Netherlands y Copenhague (Pozueta, 2008; Elenbaas \& Berends, 2012).

Estudios realizados por la Subsecretarías de espacio público, Secretarías de Movilidad y de Ciudadanía han documentado los cambios de la vida urbana en los centros de las ciudades del Valle de Aburrá. En Sabaneta y Envigado, por ejemplo, es común el uso de luces navideñas durante todo el año adornando los locales, lo que ha mejorado las visitas a los parques principales en más de un 30\% durante la semana; se han construido gimnasios al aire libre para fumadores de marihuana y sus mascotas, y para los no fumadores; lo que favorece la inclusión social, el respeto ciudadano, la convivencia pacífica y la felicidad urbana.

Sabaneta y Envigado son las ciudades del sur del área metropolitana más dinámicas en la actividad inmobiliaria junto con la gran ciudad de Medellín, con índices per cápita de crecimiento demográfico superiores al $4.5 \%$ anual en los últimos cuatro años, según el censo nacional de población y vivienda DANE (2018). La calidad del espacio urbano del centro de la ciudad y el correcto ámbito urbano han fortalecido los mejores índices de felicidad urbana en estas tres ciudades durante el 2018 y el 2019 (Muñoz Cardona \& Soto, 2020a; Muñoz Cardona 2019a; 2019b).

El ámbito urbano de los residentes de Sabaneta y Envigado se ha fortalecido, principalmente, con el uso del espacio urbano, la calidad del espacio y el respeto entre vecinos y transeúntes. La Secretaría de Convivencia Ciudadana con la misma ayuda de los vecinos atienden rápidamente cualquier malentendido entre vecinos, lo que redujo en más de un $80 \%$ las agresiones entre los años 2018-2019, tal y como lo muestran estudios de (Muñoz Cardona, 2019a). Dichas reducciones de violencia mejoran el Índice de Calidad de Vida Multivariado en ambas municipalidades, relacionadas con preguntas, tales como: ¿Ha sido usted víctima en los últimos seis meses de extorsión? ¿Ha sido usted víctima en los últimos seis meses de atraco callejero? ¿Ha sido usted víctima en los últimos seis meses de atentados contra la integridad 
física? ¿Ha sido usted víctima en los últimos seis meses de atentados a la integridad emocional como el Bullying?

Las ciudades de Medellín, Sabaneta y Envigado son los territorios donde el gobierno local más invierte parte de sus recursos de impuestos en el mejoramiento de vías, paseos peatonales verdes, fachadas de las casas, centros de la ciudad sostenible, compra de predios para la reforestación y conservación de recursos hídricos, calidad en el transporte público, manejo de residuos sólidos y calidad del aire, según estudios de (Muñoz Cardona, 2014; 2019; 2019a; $2019 b)$. Pero son a su vez, las municipalidades con mayores precios por metro cuadrado del sector inmobiliario en todo el Valle de Aburrá. A medida que crece la seguridad en las ciudadelas residenciales con mejores ofertas de espacios públicos seguros crece el valor de la administración residencial, aumenta el valor de los predios y crece el recaudo predial; tal y como lo muestran estudios del economista Eduardo Lora, Powell y Sanguinetti (2010) en el Banco Mundial sobre la calidad de vida y el precio inmobiliario.

Son las municipalidades con mayor participación de gente joven bien capacitada dentro del gobierno local. Jóvenes que a través de sus experiencias profesionales y políticas pueden transformar aún mejor el territorio. Según el estudio de investigación, en las entrevistas focales: Los Consejos Municipales de Juventud son los mejor preparados para el liderazgo comunitario por tres razones: primero, poseen menos vicios políticos; segundo, están mejor formados en las ciencias del buen gobierno y tercero, son más sensibles al mejoramiento de la calidad de vida de los barrios.

A través de Los Consejos Municipales de Juventud, los gobiernos locales liderados por jóvenes bien calificados pueden lograr la equidad social, impulsar el emprendimiento social que brinden solución a las necesidades comunales más apremiantes. Afirma Anna Yetman (1987), que las personas de formación técnica tienden a apoderarse o apropiarse más del cambio que las personas de carácter estrictamente político, sin formación técnica o mandarines; por lo que se convierten en gobiernos ejemplares en todos los demás territorios. Los jóvenes son los que mejor pueden invertir creatividad en el mejoramiento de los espacios públicos de la ciudad por su amplio conocimiento tecnológico y formación ética humana inculcada desde sus universidades e instituciones de educación.

La inversión en el mejoramiento de los espacios públicos a partir del embellecimiento de la ciudad en sus zonas céntricas ha mejorado los ingresos municipales de recaudo en predial, comercio y transporte en Guatapé y Santa Fe de Antioquia, dos de las 10 ciudades latinoamericanas intermedias más hermosas, según informe de la Cadena de noticias BBC News de Londres (5/04/2018) $)^{10}$.

A mejores espacios públicos más crece su uso, más gente concurre a caminarlos, incluso municipalidades con sus árboles emblemáticos bien cuidados de Guayacán Rosado y sus balcones florecidos en la municipalidad de Jardín se convierte en lugares destino. Ciudades donde el predio por metro cuadrado es alto por la amplia demanda habitacional, lo que facilita la actualización catastral y mejora los recursos públicos propios para inversión social (Gehl, 2014, p. 17; Muñoz Cardona, 2019a).

"Caminar es el punto de partida de todo. El hombre fue creado para caminar, y todos los sucesos de la vida nos ocurren mientras circulamos entre nuestros semejantes. La vida en toda su diversidad y esplendor se muestra ante nosotros cuando vas a pie. (...). En ciudades vitales, sostenibles, sanas y seguras, el prerrequisito para poder desarrollar una vida urbana es que existan oportunidades para caminar" (Gehl, 2014, p. 19).

La mejora en los espacios culturales de las iglesias y de la Calle Real en Santa Fe de Antioquia, cuna de los antioqueños, atrae a propios y extranjeros para recorrer y conocer los casi 100 rostros que han hecho grande la cultura más emprendedora y pujante de Colombia. Los rostros y las historias de los beatificados. Los presidentes y empresarios que le han dado honor

${ }^{10}$ Visitar página web https://www.bbc.com/mundo/noticias-america-latina-43657366 
a su patria con las inversiones en la aviación, en el transporte ferrocarril, hidroeléctricas y financiera de finales del siglo XIX y principios de siglo XX; sus escritores y pintores más famosos que han internacionalizado a Antioquia como: Don Tomas Carrasquilla, Epifanio Mejía, Gonzalo Arango, Débora Arango, Fernando Gonzáles, José María Córdoba, Rodrigo Arenas Betancur y Fernando Botero; son solo algunos de los personajes que invitan a conocerles en sus proezas (Muñoz Cardona, 2019a).

Hacer más calles alienta a que haya más tránsito; pero mejorar las posibilidades para que la gente camine, no solo vigoriza el tránsito peatonal sino que también se refuerza la vida urbana (Gehl, 2014, p. 19) alrededor de su cultura, tal y como lo muestran las inversiones de municipalidades como: San Pedro de los Milagros, La Ceja, Marinilla y Jericó en Antioquia donde lo religioso guarda sus más notables características de fe a través de fiestas y conciertos de música sacra en Marinilla o de la hermosa Iglesia del Vaticano en San Pedro de los Milagros, o del mes de las ánimas en La Ceja, o de la beatificada Madre Laura en Jericó. Inversiones en la preservación cultural que se fortalece con la unión de municipalidades para la planificación del territorio PAP, con programas como: La Ruta Lechera, Provincia de Cartama, Provincia de Aguas, Bosques y Turismo (Muñoz Cardona, 2019; 2019a).

El diseño de espacios urbanos en Medellín a lo largo de la Avenida de la Playa que integra la Congregación Empresarial Mariana, Bellas Artes, el Teatro Pablo Tobón Uribe, El Pequeño Teatro y la Corporación Universitaria Americana generan espacios culturales para la movilidad peatonal de gran riqueza artística y teatral. Avenida que hace de Medellín ciudad de la innovación cultural. A través de las escenas de teatro se educa a la población en Cultura Ciudadana. El Pequeño Teatro y el Teátrico de Medellín con obras educativas sobre la realidad de la vida en familia no cobran al ingreso del público sino al final. El asistente paga si le gustó la obra, lo que ha generado una innovación cultural muy reconocida por el premio Medellín Ciudad Discovery 2019, la ciudad es una urbe con comunidades participativas en la que el eje integrador es la resiliencia o la educación que se fortalece de las experiencias $(21 / 6 / 2019)^{11}$.

Estudios de responsabilidad ciudadana con Funda-Peatón coinciden en la necesidad de hacer más actividades sociales y culturales que promuevan el respeto y la convivencia ciudadana en el centro, bien desde las universidades cercanas a la Avenida de la Playa o bien desde los Teatros Culturales. Pero para transformar el centro, es necesario primero cambiar la cultura de los habitantes del barrio que realizan sus actividades económicas en el centro de la ciudad.

Es necesario culturizar o hacer entrar en conciencia al motociclista que vive en el barrio y circula por el centro de la ciudad en el respeto a los espacios públicos. Es necesario educar desde los barrios a través de las organizaciones sociales y juntas de acción comunal en el respeto y conservación de los espacios peatonales de la misma localidad para el disfrute de todos los residentes, por una vida digna y con valor. Es necesario la contratación de jóvenes con vocación de liderazgo social por parte de las empresas del sector privado y público y de la administración municipal para que diseñen y promuevan programas de recuperación del espacio público en sus localidades. Si se educa a los habitantes de las comunas se puede mejorar la convivencia en el centro de la ciudad, reducir los desequilibrios que deja un crecimiento de ciudad entre los espacios públicos para la movilidad peatonal y vehicular.

\section{Metodología del estudio de caso}

Si como habitantes de ciudades de aglomeración de países en desarrollo, nos preguntamos: cómo reducir los fenómenos de conurbación en movilidad, es decir, ¿cómo mejorar la cultura ciudadana en movilidad?, ¿cómo lograr una ciudadanía más responsable con el uso de los

11 Ver página web del Periódico el Colombiano: https://www.elcolombiano.com/antioquia/medellin-ganareconocimiento-internacional-ciudad-discovery-2019-EC11024660. Ver a demás la crítica realizada por RCN 10 días después del anuncio de Medellín Ciudad Discovery, en la página web consultada el 10 de julio de 2019: https://www.rcnradio.com/colombia/antioquia/polemica-por-eleccion-de-medellin-como-ciudad-discovery 
espacios públicos de movilidad? En otras palabras, ¿cómo fortalecer la cultura ciudadana para la movilidad en los barrios de las grandes ciudades del Área Metropolitana del Valle de Aburrá? Este estudio partió de suponer que en los barrios pobres de las distintas ciudades del área metropolitana viven jóvenes bien capacitados. Por lo tanto: Si se aprovecha la sensibilidad y los conocimientos del joven universitario que vive en los barrios de la ciudad es posible recuperar la cultura ciudadana y reducir las desigualdades en condiciones de vida existentes entre las diferentes localidades.

Del anterior supuesto e hipótesis, los grupos de investigación: Gobierno, Territorio y Cultura de la Escuela Superior de Administración Pública de Antioquia junto con el de Estudios Organizacionales del doctorado de la Universidad Autónoma Metropolitana de México realizaron un estudio local de felicidad urbana para la movilidad, en 15 barrios pobres de mayor densidad poblacional del Valle de Aburrá, siguiendo una metodología inductivaexploratoria.

Si en los barrios pobres de mayor densidad poblacional cohabitan jóvenes universitarios de último semestre, entonces ¿Cómo motivar el emprendimiento social juvenil en barrios de la ciudad para la movilidad y fortalecimiento de la cultura ciudadana? La investigación se basó en 710 cuestionarios realizados a jóvenes universitarios de último semestre de formación profesional de las universidades públicas de la región en las cuales estudian la mayor parte de los jóvenes de los barrios pobres.

La primera condición de encuesta fue hacerse exclusivamente a jóvenes de último semestre universitario que nacieron en el territorio y viven en los barrios de mayor densidad poblacional del área metropolitana. La segunda condición de encuesta fue tomar las universidades de Antioquia, Nacional de Colombia, Escuela Superior de Administración Pública e Instituto Tecnológico Metropolitano. La tercera condición fue seleccionar un volumen de población encuestada por profesión que garantizará un índice de confianza estadística del 95\% y un margen de error del 5\%. Se realizaron, además 8 entrevistas focales a Mesa de Jóvenes Municipales, Secretarías de Ciudadanía y de Movilidad que permitieron comprender la riqueza de ideas transformadoras de movilidad que yace en el territorio.

El estudio evaluó a través de preguntas sobre el equipamiento de ciudad los niveles de satisfacción con: la calidad de los espacios públicos en: aceras peatonales, escenarios deportivos, paseos peatonales, vías pavimentadas, ciclo rutas, señalización de vías, control de tráfico, gimnasios al aire libre, bibliotecas, museos, parques culturales, casa de la cultura y del teatro. La satisfacción de los jóvenes universitarios con la seguridad del barrio y del vecindario, la existencia de centros médicos y de hospitalización.

Las respuestas obtenidas a través de los 710 cuestionarios fueron constatadas con entrevistas a transeúntes y socializadas en foros de movilidad realizados por el Área Metropolitana con FundaPeatón. Los grupos de investigación: Gobierno, Territorio y Cultura y Estudios Organizacionales, concluyen: "El centro de la ciudad cambia si cambian las conductas de las personas que lo visitan. Y las personas que más lo visitan viven en los barrios de las distintas comunas. Es decir, si se organiza el barrio se organiza el centro de la ciudad. Si se culturiza el barrio se culturiza el centro de la ciudad".

\section{Resultados}

\subsection{Satisfacción con el equipamiento de ciudad vial y cultural del Valle de Aburrá}

La finalidad del presente estudio será conocer qué tan satisfechos están los jóvenes universitarios de último semestre que estudian en el Valle de Aburrá, con los espacios públicos que ofrece la ciudad, es decir ¿qué tan humanas son las ciudades que integran la gran ciudad del área metropolitana? Es decir, ¿qué tan diseñadas están para el disfrute de las personas? Para tal fin, se realizaron 710 encuestas para una confianza estadística del 95\% y un margen de error estadístico del $5 \%$. 
Según la Tabla 1, el 71,5\% de los jóvenes universitarios de último semestre afirman estar satisfechos y muy satisfechos con su vecindario. Dato de investigación que es muy significativo si se toma en cuenta los problemas de violencia que han vivido los diferentes barrios y comunas del área metropolitana del Valle de Aburrá en el 2018 y 2019. De hecho, el 64,8\% de los estudiantes universitarios afirman estar satisfechos y muy satisfechos con la seguridad del barrio en el que viven. El 26\% afirman estar regularmente satisfechos. Es decir, solo el 9,2\% manifiestan estar insatisfechos y muy insatisfechos.

Resultado de la investigación altamente relevante, porque muestra la importancia que puede tener el liderazgo comunal joven en sus localidades al sentirse a gusto con su vecindario en más de un 71,5\% (ver Tabla 1). Es decir, en la posible voluntad de transformación que sumado a sus capacidades de formación profesional se convertiría en un costo de oportunidad y de beneficio marginal alto.

Tabla 1. Valle de Aburrá. Satisfacción ciudadana con:

\begin{tabular}{cccc}
\hline $\begin{array}{c}\text { Nivel de } \\
\text { Satisfacción }\end{array}$ & Recursos naturales & Esparcimiento y recreación & Vecindario \\
\hline $\mathbf{1}$ & $1.9 \%$ & $2.2 \%$ & $3.7 \%$ \\
\hline $\mathbf{2}$ & $3.2 \%$ & $4.5 \%$ & $5.9 \%$ \\
\hline $\mathbf{3}$ & $18.0 \%$ & $19.5 \%$ & $18.8 \%$ \\
\hline $\mathbf{4}$ & $40.5 \%$ & $35.1 \%$ & $30.1 \%$ \\
\hline $\mathbf{5}$ & $36.4 \%$ & $38.7 \%$ & $41.4 \%$ \\
\hline Total (710) & $\mathbf{1 0 0 . 0} \%$ & $\mathbf{1 0 0 . 0} \%$ & $\mathbf{1 0 0 . 0} \%$ \\
\hline
\end{tabular}

Fuente: Centro de estudios económicos regionales CEER de la ESAP y del grupo de investigación Gobierno, Territorio y Cultura de Antioquia (2018). Nivel de satisfacción: 1 es poco satisfecho. 5 es muy satisfecho. 3 regularmente satisfecho.

En cuanto a los lugares de esparcimiento y de recreación que ofrece la gran ciudad del área metropolitana del Valle de Aburrá, el 73,8\% de los jóvenes universitarios de último semestre afirman estar satisfechos y muy satisfechos (ver tabla 1). Según los estudiantes evaluados los gimnasios en espacios abiertos han sido un gran acierto para el intercambio social de experiencias, para el encuentro comunitario en actividades lúdico-deportivas, de reconocimiento entre vecinos, de recuperación de espacios o de puntos muertos bajo los puentes, de espacios seguros para la socialización de jóvenes y adultos.

El 19,5\% califican los lugares de esparcimiento y de recreación regulares, principalmente los jóvenes universitarios de Copacabana, Caldas, La Estrella y Girardota. Solo el 4,1\% afirman que en sus localidades no tienen.

En cuanto a la satisfacción con el disfrute de los recursos naturales el 76,9\% de los jóvenes universitarios de último semestre manifiestan estar satisfechos y muy satisfechos (ver Tabla 1); sin embargo, el 18\% de los jóvenes universitarios principalmente de los municipios de Medellín e Itagüí manifiestan estar regularmente satisfechos y muy insatisfechos por la alta polución y el alto tráfico vehicular (Muñoz Cardona, 2019a; 2019b). Lo que obliga a las administraciones públicas a buscar puntos administrativos de encuentro, tanto en el ordenamiento territorial como en matriculas de nuevos vehículos, creación de nuevas vías y usos de las vías públicas para la movilidad.

En el 2019 la ciudad de Medellín comenzó con el diseño de los parques lineales verdes en el centro de la ciudad, los cuales fueron integrados a las estaciones del transporte público que cuenta con 65 vehículos eléctricos y 150 kilómetros de ciclo rutas en todo el Valle de Aburrán ${ }^{12}$.

12 Medellín, el Centro del Aburrá tiene casi 115 kilómetros en ciclo rutas, El Aburrá sur 18,7 kilómetros y el Aburrá Norte con 13, 7 kilómetros y para toda Antioquia más 500 kilómetros. Ver informe del diario del Colombiano 
Inversiones que cubren las necesidades de movilidad de más de 69.000 usuarios bajo el programa "EnCicla" que se van a triplicar con la construcción, para el 2020, de 100 estaciones de bicicletas que albergará un total de 2000 nuevos usuarios y la ampliación de las ciclo rutas caminantes. Espacios públicos que ayudan a la disminución de la contaminación ambiental, mejoran la salud pública. De igual manera, en las ciclo rutas ruedan aproximadamente 1.000 usuarios de patinetas eléctricas (Muñoz Cardona, 2019a; 2019b) ${ }^{13}$.

Obsérvese que los niveles de satisfacción de los jóvenes universitarios con los recursos, con los espacios públicos de esparcimiento y de recreación son igualmente altos. Lo que reafirma el esfuerzo que hace el Área Metropolitana en sus inversiones financiadas con el $0.2 \%$ de la sobre tasa del impuesto predial por valorización de la jurisdicción urbana y de los ingresos provenientes por multas, permisos, licencias y recaudo de las tasas retributivas al medio ambiente que oscilan entre el 0,15\% y el 0,25\%. A demás, de los recursos propios que invierten las municipalidades del área metropolitana en recursos ambientales y espacios públicos para el esparcimiento y recreación local.

Tabla 2. Valle de Aburrá. Calificación de calidad del equipamiento de movilidad

\begin{tabular}{ccccccccc}
\hline \multicolumn{2}{c}{ Calidad del tráfico } & \multicolumn{3}{c}{ Vías pavimentadas } & \multicolumn{2}{c}{ Señalización de vías } \\
\hline Bueno & Regular & Malo & Bueno & Regular & Malo & Bueno & Regular & Malo \\
\hline $52.5 \%$ & $32.5 \%$ & $15.0 \%$ & $70.0 \%$ & $25.2 \%$ & $4.8 \%$ & $67.2 \%$ & $25.7 \%$ & $5.2 \%$ \\
\hline
\end{tabular}

Fuente: Centro de estudios económicos regionales CEER de la ESAP y del grupo de investigación

Gobierno, Territorio y Cultura de Antioquia (2018).

La Tabla 2 afirma que el 52,5\% de los jóvenes universitarios califican de buena la calidad en el control del tráfico del Valle de Aburrá, es decir, la mitad. Lo que significa, que la otra mitad califica la calidad del tráfico de regular y mala. Según estudios realizados con las Secretarías de Movilidad (Muñoz Cardona, 2019a; 2019b), la insatisfacción más frecuente en la calidad de los servicios del tránsito fue la arbitrariedad en los procesos de sanciones levantadas y la corrupción de los guardas en algunas municipalidades. Las municipalidades mejor evaluadas en la calidad de los servicios del tránsito fueron en su orden: Envigado, Sabaneta, La Estrella, Caldas y Medellín.

La segunda razón principal de la insatisfacción con la calidad del control vial es por saturación de vehículos, principalmente de motos. El 60\% del parque automotor de vehículos en Medellín es de motocicletas, Según la Secretaría de Movilidad para el 1 de octubre de 2019 se contaba con 900.000 motocicletas matriculadas (Muñoz Cardona, 2019a; 2019b). La tercera razón, según las entrevistas focales realizadas en la Secretaría de Ciudadanía y Foro de movilidad de FundaPeatón es el desorden de estacionamiento de vehículos en los barrios.

Medellín, Itagüí, Girardota, Barbosa y Bello son las ciudades del área con más vehículos estacionados en las vías públicas tanto en el centro como en los barrios. Son a su vez, las municipalidades con más congestión vehicular, más accidentes de tránsito (Muñoz Cardona, 2019a; 2019b). Las ciudades de Medellín y Bello son las localidades con más reportes de accidentes peatonales fatales, según los informes entregados por FundaPeatón ${ }^{14}$ en el 2018 y

(30/12/2017) disponible en la página web: https://www.elcolombiano.com/antioquia/ciclorrutas-la-apuesta-en-el-sur-delvalle-de-aburra-EM7943413 y el informe del (11/02/2020) donde se hace un análisis de las mejores y perores ciclo rutas en la ciudad de Medellín: https://www.elcolombiano.com/antioquia/cuales-son-las-mejores-y-las-peores-ciclorrutas-demedellin-ME12439647

13 Para una mejor referencia en el crecimiento vial en el Valle de Aburrá, ver entrevista del periódico el Mundo a Eugenio Prieto el (20/02/2019) disponible en la página web: https://www.elmundo.com/noticia/El-valle-de-Aburraexpande-EnCicla-y-las-ciclo-rutas/375812

${ }^{14}$ Ver informe del diario El Colombiano el (03/10/2019): https://www.elcolombiano.com/antioquia/accidentes-de-motosen-medellin-que-se-esta-haciendo-para-reducir-las-victimas-mortales-FP11695077 
2019. De allí, que el 32,5\% de los jóvenes universitarios del área metropolitana afirmen que la calidad del control de tráfico es regular; el 11,6\% de mala y el 3,4\% la califica de inexistente, es decir los jóvenes universitarios están insatisfechos con la calidad en el control de tráfico (ver Tabla 2).

De igual manera, algunos estudiantes afirman que las cámaras de control de velocidad de tráfico no logran el objetivo esperado por la alta existencia de vehículos que sobre dimensionan la estructura vial disponible del área metropolitana y no permiten excesos de velocidad. Las fotos multas generan ganancia a los empresarios dueños de las cámaras y a los recaudos fiscales de la administración municipal, pero no ayudan a la solución del problema vehicular en la región. Las muertes fatales siguen en aumento (Muñoz Cardona \& Soto, 2020a; Muñoz Cardona, 2019a; 2019b).

En cuanto a la calidad de las vías pavimentadas en todo el Valle de Aburrá, el 70\% de los jóvenes universitarios de último semestre afirman que son buenas, el 25,2\% dicen que son regulares, el 3,8\% dicen que son malas y el 1\% dicen que no existen, es decir, el 4,8\% de las vías están en mal estado. En cuanto a la señalización de las vías que faciliten la movilidad, coadyuven a la disminución de accidentes, ayuden a la correcta circulación de vehículos y movilidad de los peatones; el 67,2\% de los estudiantes encuestados afirman que son buenas, el $25,7 \%$ dicen que son regulares y el 5,2\% dicen que son malas y el 1,9\% afirma que son inexistentes (ver Tabla 2).

Tabla 3. Valle de Aburrá. Calificación de calidad de las aceras peatonales

\begin{tabular}{cccccccc}
\hline & \multicolumn{3}{c}{ Escenarios deportivos } & \multicolumn{3}{c}{ Aceras peatonales } \\
\hline Bueno & Regular & Malo & No tiene & Bueno & Regular & Malo $\begin{array}{c}\text { No } \\
\text { tiene }\end{array}$ \\
\hline $81.3 \%$ & $16.2 \%$ & $1.8 \%$ & $0.7 \%$ & $67.1 \%$ & $29.1 \%$ & $2.7 \%$ & $1.1 \%$ \\
\hline
\end{tabular}

Fuente: Centro de estudios económicos regionales CEER de la ESAP y del grupo de investigación Gobierno, Territorio y Cultura de Antioquia (2018).

Es decir, los barrios y los centros de las ciudades del área metropolitana del Valle de Aburrá poseen buenas vías y están bien señalizadas. Más del $90 \%$ de los habitantes de los barrios manifiestan estar muy satisfechos por la calidad de los servicios de acueducto, alcantarillado, gas por red, servicios sanitarios y de transporte público -el metro, las Escaleras eléctricas, los Metro Cables, las Líneas Férreas Comerciales, Metro Plus, y Servicio integrado de buses eléctricos- (Muñoz Cardona, 2019a; 2019b).

En cuanto aceras peatonales que sirvan a la movilidad del peatón y faciliten una movilidad segura, el 67,1\% de los estudiantes universitarios de último semestre del área metropolitana afirman que son buenas, incluso están señalizadas para personas invidentes y de movilidad reducida; pero, el 29,1\% dicen que son regulares porque adolecen de espacios para el peatón (ver Tabla 3). La razón fundamental es que la economía informal se apropió de los espacios públicos (FundaPeatón, 2019). En otras palabras, en equipamiento de infraestructura vial el área metropolitana es buena, logra abastecer necesidades sociales y dar una amplia cobertura, pero no con calidad, por la falta de control sobre el uso del espacio público (Muñoz Cardona \& Soto, 2020a; Muñoz Cardona, 2019a; 2019b).

En cuanto a la calidad de los escenarios deportivos, el 81,3\% dicen que son buenos, el área metropolitana se caracteriza por tener abundantes escenarios deportivos: excelentes canchas de fútbol, voleibol y basquetbol. La gran mayoría de las canchas de fútbol son en grama sintética, con el fin de mantener la salud de los vecinos que viven cerca a dichas unidades deportivas (Muñoz Cardona \& Soto, 2020a). El 16,2\% dicen que son regulares. El 0.7\% dicen que no tienen y el 1,8\% que son malas (ver Tabla 3). En otras palabras, área metropolitana tiene buenos y abundantes escenarios deportivos. 
Tabla 4. Valle de Aburrá. calificación de calidad de los espacios culturales

\begin{tabular}{|c|c|c|c|c|c|c|c|}
\hline \multicolumn{3}{|c|}{ Calidad de las bibliotecas } & Bueno & Regular & Malo & No tiene & $\begin{array}{c}\text { Total } \\
\text { general }\end{array}$ \\
\hline \multicolumn{3}{|c|}{ Valle de Aburrá } & $66.4 \%$ & $22.9 \%$ & $4.5 \%$ & $6.2 \%$ & $100.0 \%$ \\
\hline \multicolumn{2}{|c|}{ Teatros } & \multicolumn{2}{|c|}{ Parques culturales } & \multicolumn{2}{|c|}{ Museos } & \multicolumn{2}{|c|}{ Casa de la cultura } \\
\hline SI & NO & SI & NO & SI & NO & SI & NO \\
\hline $61.6 \%$ & $38.4 \%$ & $83.0 \%$ & $17.0 \%$ & $62.9 \%$ & $37.1 \%$ & $71.4 \%$ & $28.6 \%$ \\
\hline
\end{tabular}

Fuente: Centro de estudios económicos regionales CEER de la ESAP y del grupo de investigación Gobierno, Territorio y Cultura de Antioquia (2018).

En cuanto a los escenarios culturales que sirven a la buena formación profesional y de los ciudadanos, por cuanto coadyuvan a generar una ciudadanía respetuosa, se tienen: el 66,4\% de los jóvenes estudiantes de último semestre universitario afirman que el área metropolitana posee buenas bibliotecas, principalmente en: Medellín, Caldas, Envigado, Sabaneta e Itagüí. El 22,9\% afirman que son regulares, principalmente los estudiantes de Barbosa y de Bello; el 4,5\% que son malas, especialmente los estudiantes de los municipios de Girardota y Copacabana, otros afirman que no tienen, principalmente los estudiantes encuestados de los corregimientos. De manera general, podría concluirse que el área metropolitana logra un cubrimiento bueno en un 89,3\%, ver tabla 4, (Muñoz Cardona \& Soto, 2020a; Muñoz Cardona, 2019a; 2019b).

En cuanto a la oferta de parques culturales y recreativos el área metropolitana logra una excelente cobertura con: CEDEZOS, UVAS, Andrés Bello, Débora Arango, Fernando Gonzales, El Dorado, Parque Arví, Casa Marco Fidel Suarez, Casa Fernando Gonzales, Casa de la Memoria, Parque Explora, Casas de Teatro y RUTAN, entre otros. El 83\% de los estudiantes de último semestre afirman disfrutar de dichos recursos. El 71,4\% de los estudiantes universitarios encuestados afirman que los municipios del área metropolitana tienen Casa de la Cultura. El $61,6 \%$ afirman que tienen Teatros y el 62,9\% Museos.

En otras palabras, el área metropolitana tiene jóvenes bien formados tanto en lo académico como en la sensibilidad ética con el otro, que podrían ayudar a la reconstrucción del tejido social a partir de la instrucción de la ética de la responsabilidad ciudadana en el respeto de los espacios públicos. Las empresas y las administraciones públicas podrían aprovechar la inversión realizada por los 10 municipios y el Área Metropolitana en infraestructura de ciudad, motivando el emprendimiento social y el liderazgo comunitario. Inversión que ayudaría a reducir el desempleo joven; lo que crearía nuevas culturas políticas y de ciudad.

No deja de ser relevante que más del $28 \%$ de los estudiantes afirmen que en sus municipios no hay Teatros y Museos por cuanto son instituciones promotoras de arte musical, artes escénicas y de formación cultural (ver Tabla 4). Los municipios que menos equipamiento tienen afirman los estudiantes, son: Girardota, Barbosa y La Estrella (Muñoz Cardona \& Soto, 2020a; Muñoz Cardona, 2019a; 2019b).

\section{Conclusión}

De acuerdo con los resultados de la investigación se puede afirmar que la población encuestada se encuentra satisfecha con la gestión pública realizada en el Valle de Aburrá en lo que corresponde al equipamiento vial $(95,2 \%)$ y cultural de la ciudad $(83,3 \%)$. La creación de una mayor cantidad de áreas públicas que promueven el esparcimiento, la recreación y el arte, tales como, gimnasios al aire libre, cafeterías a espacio abierto y la recuperación de parques que son parte del espacio público, son algunas de las iniciativas gubernamentales que han tenido éxito entre la población, y han motivado un cambio en las actitudes de los ciudadanos hacia el cuidado y el respeto de los bienes públicos (Cultura Metro). De este modo, seguir construyendo espacios públicos en los que se integre lo intelectual, lo cultural y lo artístico, es una de las fórmulas de éxito en la construcción de ciudades para la felicidad urbana. 
Sin embargo, los desafíos que sigue enfrentando la ciudad son muchos, en este caso, la movilidad pública es un aspecto que requiere atención urgente, debido a que, aunque se han desarrollado políticas públicas que han mejorado la situación de tráfico en las áreas estratégicas de interés económico para la ciudad, el control del tráfico vehicular en los barrios, es un problema crítico que se ha convertido en uno de los mayores detonantes de conflicto social y reductores de la calidad de vida de los ciudadanos. Para desalojar las zonas peatonales es necesaria la construcción de parqueaderos en los barrios y buscar alternativas para evitar que la economía informal se apropie de espacios públicos como parques y andenes.

De acuerdo con las respuestas obtenidas, se considera que la creación de entornos sociales favorables a la convivencia, conducen a los ciudadanos a un mayor disfrute de los recursos naturales, servicios de recreación, arte y deporte que la ciudad les ofrece, lo que a su vez no sólo contribuye a unos mayores niveles de felicidad urbana, sino que se logran elevar los sentimientos de simpatía y acción solidaria entre las personas.

De este modo, si se logra transformar la calidad de vida desde los barrios de la ciudad, los efectos positivos de esta transformación también tendrán repercusiones positivas en las áreas estratégicas de interés económico para la ciudad debido a que son los mismos ciudadanos quienes mediante su liderazgo comunitario se convierten en agentes activos en la construcción de una mejor sociedad.

\section{Referencias}

Bosselmann, P. (1998). Representation of places: reality and realism in city design. Berkeley: University of California Press.

Campanella, T. (1995). La política. Barcelona: Ediciones Altaya.

Camps, V. \& Giner, S. (2014). Manual de Civismo. Barcelona, España: Ariel.

DANE. (2018). Censo Nacional de Población y Vivienda. Microdatos anonimizados por manzana. Bogotá: Gobierno de Colombia y el Departamento Nacional de Estadística.

Duque, Márquez I. (2018). Efecto Naranja. Innovación e ideas políticas en la sociedad poscrisis. Bogotá: Géminis, Planeta.

El Colombiano. (21/06/2019). Medellín, reconocida como Ciudad Discovery 2019. Periódico El Colombiano.

El Mundo.Com. (20/03/2017). En Medellín así es la experiencia ciudadana de felicidad sentida. Periódico El Mundo.

Elenbaas, P. \& Berends, L. (2012). A city in motion. Cloudless Amsterdam. Netherlands: Uitgeverij Bas Lubberhuizen.

Fernández, Correa. L. (2019). Derecho a la ciudad desde el espacio público efectivo e incluyente en Medellín. Medellín: Universidad de Antioquia.

FundaPeatón. (2019). Activos por ciudades caminables. Medellín: Área Metropolitana del Valle de Aburrá.

Gehl Architects. (2009). Downtown Seattle public space and public life. Seattle: International Sustainability Institute.

Gehl, J. (2010). Cities for People. Washington: Island Press.

- (2014). Ciudades para la gente. Argentina: Infinito y ONU Hábitat.

Jacobs, J. (1961). The death and life of great American cities. New York: Random House. 
- (2011). Muerte y vida de las grandes ciudades. Madrid: Capitán Swin Libros.

Le Corbusier. (1980). Concerning town planning. New Haven: Yale University Presss.

Ley № 1625 de 2013. Ley de Áreas Metropolitanas “Por la cual se deroga la Ley Orgánica 128 de 1994 y se expide el régimen para las áreas metropolitanas". Bogotá, Ministerio del Interior.

Lora, E. \& et al. (2010). "The Quality of Life in Latin American Cities: Markets and Perceptions". Washington D.C.: Inter-American Development Bank and Word Bank.

Marín, Morales A. (2019). El sueño colombiano: dibujando las nuevas rutas. Revista de (in) movilidad $e$ inmigraciones ROUTED. Disponible en: https://www.routedmagazine.com/colombian-dream

Maslow, A. (2008). La personalidad creadora. Barcelona, España: Kairos, S.A.

Max Neef, M. \& et al. (1994). Desarrollo a escala humana: aplicaciones y algunas reflexiones. Barcelona: Icaria Editorial.

Muñoz Cardona, Á.E. (2017). Ética de la responsabilidad ciudadana: un camino para la paz. Bogotá: Escuela Superior de Administración Pública, VU University Amsterdam.

- (2019). El Área Metropolitana del Valle de Aburrá y las Provincias. Retos de Unión Social y Política. Reflexión Política, 21(41), 175-189.

- (2019a). Felicidad urbana. Área metropolitana del Valle de Aburrá. Revista En-Contexto, Revista de investigación en Administración, Contabilidad, Economía y Sociedad, 7(11), 113-147.

- (2019b). Felicidad urbana en el Eje Cafetero. Revista de Antropología y Sociología: Virajes, 21(1), 197228.

Muñoz Cardona, Á. \& Quintero, H. (2020). Las utopías del bienestar general. De la idea de ciudad de Thomas More a Yuval Harari. Reflexión Política, 22(44), 135-145.

Muñoz Cardona, Á. \& Martínez, L. (2020a). Emprendimiento social y felicidad urbana. Revista SUMMA, 2(1), 127-169.

Osorio, Montoya. M. (11/02/2019). Imprudencia vial cobró en dos años vida de 225 peatones en Medellín. Diario El Tiempo.

Plan de Desarrollo Municipio de Medellín. (2016). Medellín cuenta con vos 2016-2019. Medellín: Alcaldía de Medellín.

Prieto, E. (2017). La fuerza de la asociatividad. El Metropolitano del Valle de Aburrá. Medellín: Editorial, Área Metropolitana Valle de Aburrá.

Pozueta, J. (2008). La experiencia internacional en peajes urbanos. Cuadernos de Investigación Urbanística, (58), 3-112.

Restrepo, N. (2011). Empresariado antioqueño y sociedad, 1940-2004: influencia de las élites patronales de Antioquia en las políticas socioeconómicas colombianas. Medellín: Universidad de Antioquia, Colección Clio.

Ribetto, A. (2014). Gestos mínimos y pedagogía de las diferencias. Polis Revista Latinoamericana, 37, 1-11.

Sófocles. (1966). Edipo en colono. París: Alphonse Dain.

Smith, Adam. (1997). La Teoría de los sentimientos morales. Madrid: Alianza Editorial.

- (1997a). Investigación sobre la naturaleza y causas de la Riqueza de las Naciones. México: Fondo de la Cultura Económica. 
Stiglitz, J. \& et al. (2015). Informe de la Comisión sobre la Medición del Desarrollo Económico y del Progreso Social. Sintesis y recomendaciones. Francia: CMPEPS.

- (14/04/2014). La ciudad y las desigualdades. Conferencia de apertura, Foro Urbano Mundial. Medellín: Alcaldía de Medellín.

Yeatman, A. (1987). The Concept of Public Management and the Australian State in the 1980s. Australian Journal of Public Administration, 46(4): 339-353.

\section{(9) $\odot \Theta \Theta$}

(C) Attribution-NonCommercial-NoDerivatives 4.0 International (CC BY-NC-ND 4.0) https://creativecommons.org/licenses/by-nc-nd/4.0/ 